\title{
THE INFLUENCE OF FUNCTIONAL MOVEMENT SCREEN RESULTS ON THE FREQUENCY OF SPORTS INJURIES IN SOCCER PLAYERS
}

\author{
Krzysztof Kryger,, A, B, C, D Andrzej Wieczorek, 2, A, C, D Jacek Wieczorek, 2, A, C, D \\ Robert Śliwowski2, A, B, C, D, E
}

\author{
${ }^{1}$ Wielkopolskie Centrum Rehabilitacji i Profilaktyki Niepełnosprawności Dzieci i Młodzieży, Poland \\ ${ }^{2}$ AWF Poznań, Zakład Teoriii Metodyki Zespołowych Gier Sportowych, Poland \\ ${ }^{\text {A }}$ Study Design; ${ }^{B}$ Data Collection; ${ }^{C}$ Statistical Analysis; ${ }^{D}$ Manuscript Preparation; ${ }^{E}$ Funds Collection \\ Address for correspondence: \\ Robert Śliwowski \\ AWF Poznań, Zakład Teorii Metodyki Zespołowych Gier Sportowych \\ Królowej Jadwigi 27/39, 61-871 Poznań, Poland \\ E-mail: sliwowski@awf.poznan.pl
}

\begin{abstract}
Ahstract Functional Movement Screen (FMS) is a functional screen test of the motor system which is steadily gaining recognition and popularity among individuals interested in prevention of sports injuries. The FMS test battery includes seven mutually related motor activities to analyse the quality of basic movement patterns. An in-depth interpretation of the performed test design provides good conditions to determine the weakest links in the kinematic chain and to estimate the risk of injury.

The objective of this study was to determine the effect of the FMS test results on frequency of sports injuries in soccer players. With the main objective of the study in mind the following research hypothesis was formulated: "a group of players in the lowest interval (14-17 FMS test points) will have a high frequency of injuries in comparison to a group in the upper interval (18-21 points in the FMS test)". The tests were carried out on a group of 102 younger and older junior soccer players representing the Soccer Academy of KKS Lech Poznań. For that the test design with FMS test procedure was used, followed by a six month period in which the injuries of the individuals in the study group were recorded.

The research hypothesis was not confirmed. In the analysis of the results no statistical significance was noted between the total number of points obtained in the FMS test and the number of injuries. It was noted that the number of injuries was statistically significantly correlated with the results of the Shoulder Mobility test of the right side (for all participants and for the players in the lower interval), Hurdle Step test of the left side (for a group of players in the lower interval), and the In-line Lunge test of the left side (for upper interval players). The results of the single variable logistic regression showed that injuries occurred more often in players of the lower interval. A forest plot indicates the direction of the increased risk of injury in players in the lower interval of points: $\mathrm{OR}=1.14(95 \% \mathrm{CL} ; 0.71: 1.83)$.
\end{abstract}

Key Worlls FMS, trauma risk, junior players

\section{Introduction}

For many years soccer has been the world's most popular sport discipline, with a steadily increasing number of new players. The report of the Polish Central Statistical Office (GUS) on physical culture in 2016 indicates 
that in Poland physically active people are most interested in team sports (58.4\% of exercising people), of which soccer accounts for as much as 39.5\% (Główny Urząd Statystyczny, GUS, 2017 yr.). At the moment a constant development of tactical systems and the motor preparation of players can be observed. The consequence of these phenomena is an increase in the pace of play which requires the players to shorten their reaction time to an absolute minimum. As a result soccer has become a sort of martial art, leading to an increase in the number of injuries and accidents in players every year. The financial aspect associated with the costs of treatment is particularly noticeable in smaller clubs and organizations, which cannot afford to cover the costs of a player's recovery, as a consequence extending the period of player's absence from sports activities (Hadała, Bieganowski, Wierzbowska, de Bernardo Tajedor, Snela, 2006; Żołnowski, Wrona-Żołnowska, Gębska, Wojciechowska, Żyżniewska-Banaszak, 2013).

The study of M. Hadała et al. (2006) shows that more than $85 \%$ of players sustain an injury during a season. The body part most susceptible to injury in soccer is the lower extremity $(97 \%)$, while other injuries were noted within the trunk, head and the upper extremity. This is a consequence of acute mechanical injuries usually related to duels with the opposition players, but also as a result of excessive training and match loads, as a result of which individuals are overtrained and initially minor microinjuries within the motor organ accumulate. Athlete's injuries may be defined as acute or chronic. The former in the soccer world are mainly associated with direct confrontation with the opposition player and are of one-time character manifested by sudden acute symptoms. Chronic injuries however are difficult to determine in time, develop gradually, even for years as a result of cumulative microinjuries which did not heal or as a result of incorrect movement patterns practiced for a long time. The analysis of statistics of the World Cup in Japan and South Korea shows match situations in which players were injured. The results show clearly that as many as $73 \%$ of all recorded injuries during 64 World Cup matches occurred as a result of contact between players of opposite teams (Adamczyk, 2005). The group of injuries (27\%), which did not result from the interference of second parties, is extremely significant. This situation is very worrying and may indicate that such a high percentage of injuries is a consequence of the nature of dynamics of play in modern soccer. Identical statistical studies carried out in England show that as many as 59\% of all injuries were contactless, and the mechanism of injury resulted from motor activity of players (Adamczyk, 2005). Nowadays a very concerning phenomenon may be observed, namely that $85 \%$ of injuries in the group of people playing soccer are injuries of young players, below 23 years of age (Żołnowski et al., 2013). Bearing in mind that a sustained injury in itself is a factor increasing the risk of another trauma in the motor system, more emphasis should be put on prevention of injuries in young players (Grygorowicz, Głowacka, Wiernicka, Kamińska, 2010).

Due to the characteristics of the motor activity and effort, soccer can be classified as a endurance and speed discipline. It is assumed that during a match a player performs approximately 1,000 various motor activities related to the unique character of moving on the pitch (Bangsbo, Mohr, Krustru, 2006). Team games are characterized by a whole range of complex functional movements which suggests that the player's activity is a three-plane movement act. The system of neuromuscular control supervises stimulation of muscle groups to various functions during activities in the conditions of an open and closed biokinematic chains (Rzepka, Grzybczak, Więcek, 2009). In the analysis of the complex term which is functional movement (performed simultaneously in three planes) one can conclude that it is a total of actions of various muscle groups playing various functions in relation to each other (stabilization, agonists, antagonists, synergists), which is expressed as a correct performance of a movement pattern. The function of small specialized muscle groups, the actions of which consists in stabilization of individual links of the kinematic chain during dynamic activity, is extremely significant for the effectiveness of the motor organ 
during three-plane motor activities. Disturbed function leads to creation of replacement compensatory movements. The consequence is the inability to perform an effective movement pattern correctly, resulting in unfavorable conditions predisposing to damage, overstrain changes and more compensation within the motor organ (Kiesel, Plisky, Butler, 2011; Kiesel, Plisky, Voight, 2007; Rzepka, et al., 2009).

Functional Movement Screen created by Gray Cook is a screen test of seven movement patterns. The tests use various positions and movements closely related to correct development and progress. It was noted that fundamental movement patterns tested by FMS are the basis for much more complex activities practiced in everyday life and in sport. The greatest advantage of the screen test is the fact that FMS is an simple and easily available way to analyze the quality of movement patterns, mobility with stability, and co-ordination of the neuromuscular system. The concept of the test is based on seven movement tasks and three additional pain-provocation tests identifying any deficits and asymmetries, making it possible to assess the risk of injury in a player and creating beneficial conditions to set up a long-term corrective training plan. A significant number of publications using FMS focus on the issue of modification of training programs, progress in the quality of movement patterns, mobility and stability, and the system of neuromuscular control of athletes. According to the reports the FMS test makes it possible to identify individuals with potentially higher risk of injury. The main intention of this study was to analyze the effect of FMS test results on the frequency of sports injuries in soccer players. The assumed research hypothesis was that "a group of players in the lower range (14-17 points in the FMS test) should displays a higher frequency of injury compared to the group of the group in the upper range (18-21 points in the FMS test)" (Adamczyk, Pepłowski, Boguszewski, Białoszewski, 2012; Lemiesz et al., 2013; Minick et al., 2010).

\section{Material and methods}

\section{The studly group}

The study material consisted of a group of 102 trained soccer players of Academy KKS Lech Poznań with its seat in Wronki, representing older and younger junior teams. The oldest players in the group were born in 1998 and the youngest in 2001. Every week the group took part on average in five training units (in total 8 hours) and one match which usually took place on Saturday or Sunday. After every league game activities related to sports recovery were immediately implemented. The day after the game was usually free from activities and the focus was on players' recovery. The FMS test was performed from 25 to 20 June 2016. In the following 6 months, that is from 1 July to 31 December 2016, the injuries sustained by the studied individuals were noted.

The anthropometric characteristics of the studied players and their training history are presented in Table 1. The players were additionally divided into a group of players who were injured and a group of injury-free players.

Table 1. Anthropometric characteristics and training history of the studied players of KKS Lech Poznań (Junior A,B)

\begin{tabular}{|c|c|c|c|c|}
\hline \multirow{2}{*}{ Variable } & Height (cm) & Weight (kg) & BMI & Training history (years) \\
\hline & $x \pm \delta$ & $x \pm \delta$ & $x \pm \delta$ & $x \pm \delta$ \\
\hline \multirow{2}{*}{ All players, $N=102$} & 176.37 & 67.65 & 21.76 & 9.35 \\
\hline & 0.61 & $7,354.87$ & 325.69 & 94.64 \\
\hline \multirow{2}{*}{ Injured players, $N=79$} & 176.82 & 67.96 & 21.74 & 9.41 \\
\hline & 0.43 & $5,450.89$ & 241.79 & 70.20 \\
\hline \multirow{2}{*}{ Injury-free players, $N=23$} & 174.70 & 66.61 & 21.83 & 9.15 \\
\hline & 0.16 & $1,871.48$ & 83.81 & 23.23 \\
\hline
\end{tabular}




\section{Study methods}

\section{Functional Movement Screen (FMS)}

The study group underwent the Functional Movement Screen test using a ready "FMS Kit" in the period from 25 to 30 June 2016. Each individual performed seven motor tests assessing the quality of basic movement patterns, stability, joint mobility, and neuromuscular control. Additionally, three pain-provocation tests were performed. The activities were analyzed in two planes of movement (frontal and sagittal). The studied individuals had three attempts for each basic test and the best result was recorded. In asymmetric tests, assessing the left and right side separately, the side with the lower number of points was recorded in the overall FMS test results. Each movement pattern was assessed in the four-degree scale from 0 to 3 points according to the generally accepted principles:

3 points - for correct performance of the functional pattern;

2 points - for the ability to perform the functional pattern with some compensation;

2 point - if the individual was unable to perform the pattern;

0 points - if the individual reported pain at any point of the test.

The highest possible score to be achieved by the study group in the whole FMS test was 21 points. In case of an individual reporting pain in additional pain-provocation tests 0 points were scored for a given movement pattern.

FMS test battery consists of:

Test 1 Deep Squat

Test 2 Hurdle Step

Test 3 In-line Lunge

Test 4 Shoulder Mobility

+ pain-provocation test - irritation, impingment syndrome

Test 5 Active Straight Leg Rise

Test 6 Trunk Stability Push-up

+ pain-provocation test - active extension of lumbar spine

Test 7 Rotational Stability

+ pain-provocation test - global stretch in quadruped position (Adamczyk et al., 2012; Lemiesz et al., 2013; Rzepka et al., 2009).

The FMS test was followed by a six month period (1 July to 31 December 2016) when players' health was monitored and injuries were recorded in detail in special research cards.

\section{Statistical methods}

All statistical analyses were performed using STATISTICA 10.0 for Windows Version (SPSS Inc., Chicago, II, USA). The following descriptive statistics were calculated for all studied individuals and for all subgroups: arithmetic mean, standard deviation, minimum and maximum. For all studied parameters the consistency with normal distribution was assessed using Shapiro-Wilk test. Relations between the studied FMS parameters and the number of injuries were assessed using the correlation coefficient. For variables with normal distribution the analysis was performed using Pearson's correlation coefficient. If one of the variables did not meet the criteria for normality, Spearman's correlation coefficient was used. In order to determine the probability of injury in players in individual 
groups (so called lower range, FMS score of 14-17 and the upper range, FMS score of 18-21) univariate regression model was used and a forest plot for this model. The level of statistical significance was defined as $p<0.05$.

\section{Results}

\section{Overall FMS results}

Table 2 shows mean scores in individual tests, mean total FMS score and mean number of injuries of players for all participants.

Table 2. Descriptive statistics for all participants $(n=102)$

\begin{tabular}{lcccc}
\hline & Variable & Minimum & Maximum & Standard deviation \\
\hline Deep Squat & 2.19 & 1 & 3 & 0.502 \\
Hurdle Step L & 2.39 & 2 & 3 & 0.491 \\
Hurdle Step R & 2.58 & 2 & 3 & 0.496 \\
In-line Lunge L & 2.76 & 2 & 3 & 0.432 \\
In-line Lunge R & 2.82 & 2 & 3 & 0.383 \\
Shoulder Mobility L & 2.96 & 2 & 3 & 0.195 \\
Shoulder Mobility R & 2.98 & 2 & 3 & 0.139 \\
ASLR L & 2.47 & 1 & 3 & 0.609 \\
ASLR R & 2.54 & 1 & 3 & 0.520 \\
Trunk Stability Push-up & 2.77 & 1 & 3 & 0.491 \\
Rotational Stability L & 2.47 & 2 & 3 & 0.502 \\
Rotational Stability R & 2.28 & 2 & 3 & 0.453 \\
\hline Total & 17.70 & 14 & 21 & 1.756 \\
\hline Number of injuries & 1.28 & 0 & 3 & 0.948 \\
\hline
\end{tabular}

In the analysis of the Functional Movement Screen scores for the whole study group the lowest values were noted in the Deep Squat. The mean score in the Deep Squat for all participants was 2.19 points. The highest values were noted in the Shoulder Mobility test. In the Shoulder Mobility test mean scores of 2.96 and 2.98 were noted for the left and right sides, respectively. In the Deep Squat, Trunk Stability Push-up and ASLR tests for both sides, some players were noted to score 1 point, which indicates incorrect performance of the movement task. For other tests the players scored at least 2 points. The mean score for the whole test for the group was 17.7 points. and the mean number of injuries per one player was 1.28 .

Table 3 presents mean scores in individual tests, mean total FMS score and mean number of injuries of players of the lower range (14-17 points).

In the analysis of the FMS scores of the group of players in the lower range (with the score of 14-17 points) it can be noted that the Deep Squat test featured the lowest scores. Mean score in the Deep Squat test of the analyzed group was 1.93 points. The group had highest scores in the Shoulder Mobility tests. In the Shoulder Mobility tests mean scores of 2.91 and 2.96 points were noted for the left and right sides, respectively. For the Deep Squat, Trunk Stability Push-up and ASLR tests for both sides, some players had a score of 1 point which indicates incorrect performance of the movement pattern. For other tests movement patterns performed by the representatives of the 
lower range were given a score of at least 2 points. The mean score for the whole test for the participants in the lower range was 16.07 points and the mean number of injuries per one player within the analyzed group was 1.27.

Table 3. Descriptive statistics of the group of players in the lower range (14-17 points, $n=45)$

\begin{tabular}{|c|c|c|c|c|}
\hline Variable & Mean & Minimum & Maximum & Standard deviation \\
\hline Deep Squat & 1.93 & 1 & 3 & 0.393 \\
\hline Hurdle Step L & 2.07 & 2 & 3 & 0.252 \\
\hline Hurdle Step R & 2.29 & 2 & 3 & 0.458 \\
\hline In-line Lunge L & 2.53 & 2 & 3 & 0.505 \\
\hline In-line Lunge $\mathrm{R}$ & 2.6 & 2 & 3 & 0.495 \\
\hline Shoulder Mobility L & 2.91 & 2 & 3 & 0.288 \\
\hline Shoulder Mobility R & 2.96 & 2 & 3 & 0.208 \\
\hline ASLRL & 2.07 & 1 & 3 & 0.580 \\
\hline ASLR R & 2.27 & 1 & 3 & 0.495 \\
\hline Trunk Stability Push-up & 2.56 & 1 & 3 & 0.624 \\
\hline Rotational Stability L & 2.27 & 2 & 3 & 0.447 \\
\hline Rotational Stability R & 2.09 & 2 & 3 & 0.288 \\
\hline Total & 16.07 & 14 & 17 & 1.075 \\
\hline Number of injuries & 1.27 & 0 & 3 & 0.889 \\
\hline
\end{tabular}

Table 4 shows mean scores for individual tests, mean total FMS score and mean number of injuries in the group of upper range players (18-21 points)

Table 4. Descriptive statistics of the players in the upper range $(18-21 \mathrm{pts}, \mathrm{n}=57)$

\begin{tabular}{|c|c|c|c|c|}
\hline Variable & Mean & Minimum & Maximum & Standard deviation \\
\hline Deep Squat & 2.39 & 2 & 3 & 0.491 \\
\hline Hurdle Step L & 2.65 & 2 & 3 & 0.482 \\
\hline Hurdle Step R & 2.81 & 2 & 3 & 0.398 \\
\hline In-line Lunge L & 2.93 & 2 & 3 & 0.258 \\
\hline In-line Lunge $R$ & 3.00 & 3 & 3 & 0.000 \\
\hline Shoulder Mobility L & 3.00 & 3 & 3 & 0.000 \\
\hline Shoulder Mobility R & 3.00 & 3 & 3 & 0.000 \\
\hline ASLRL & 2.79 & 2 & 3 & 0.411 \\
\hline ASLR R & 2.75 & 2 & 3 & 0.434 \\
\hline Trunk Stability Push-up & 2.93 & 2 & 3 & 0.258 \\
\hline Rotational Stability L & 2.63 & 2 & 3 & 0.487 \\
\hline Rotational Stability R & 2.44 & 2 & 3 & 0.501 \\
\hline Total & 18.98 & 18 & 21 & 0.916 \\
\hline Number of injuries & 1.30 & 0 & 3 & 0.999 \\
\hline
\end{tabular}

The analysis of the FMS scores in the group of the upper range players (with the score of 18-21 points) shows that the lowest scores were noted in the Deep Squat test. The mean score in the Deep Squat test of the analyzed 
group was 2.39 points. The highest scores were noted in the Shoulder Mobility tests and In-line Lunge tests. In the Shoulder Mobility test mean values of 3 points for both sides were noted, which indicates faultless performance of the movement pattern by the analyzed group of upper range players. In the In-line Lunge test mean value of 3 and 2.93 points were noted for the right and left sides, respectively. The analyzed group of players had a mean score for the whole test of 18.98 points, and the mean number of injuries sustained per one player was 1.3.

\section{Corpelations between the FMS test scopes and the number of injuries}

Table 5 presents the results of Spearman's rank correlation test taking into account the total FMS score and the number of injuries.

Table 5. Spearman's rank correlation for FMS test scores and the number of injuries

\begin{tabular}{lcccc}
\hline \multicolumn{1}{c}{ Pair of variables } & Size of group & $\begin{array}{c}\text { Spearman's R correlation } \\
\text { coefficient }\end{array}$ & t test & Value of $p$ \\
\hline $\begin{array}{l}\text { FMS vs. number of injuries } \\
(\text { all) }\end{array}$ & 102 & 0.05 & 0.47 & 0.6404 \\
\hline $\begin{array}{l}\text { FMS vs. number of injuries } \\
\text { (players with the score of 14-17 pts.) })^{b}\end{array}$ & 45 & -0.10 & -0.66 & 0.5161 \\
\hline $\begin{array}{l}\text { FMS vs. number of injuries } \\
\text { (players with the score of 18-21 pts.) })^{c}\end{array}$ & 57 & 0.18 & 1.37 & 0.1770 \\
\hline
\end{tabular}

Statistically significant $p<0.05$.

a Spearman's rank correlation between the total FMS score of all players and the number of injuries.

'Spearman's rank correlation between the total FMS score of lower range players (14-17 points) and the number of injuries.

'Spearman's rank correlation between the total FMS score of the upper range players (18-21 points) and the number of injuries.

In the analysis of the results of testing pairs of variables no statistically significant correlation was noted for the total score in the FMS tests and the number of injuries. For the whole group $(n=102)$ the correlation coefficient was 0.05 and was not statistically significant $(p=0.6404)$. For the group of lower range players (with scores of $14-17$ points) the correlation coefficient was -0.10 and did not show statistically significant correlations, either ( $p=0.5161$ ). For the participants in the upper range (with scores of 18-21 points) the correlation coefficient was 0.18 which also shows no statistical significance $(p=0.1770)$.

Table 6 shows the results of Spearman's rank correlation test taking into consideration the number of points scored in individual tests and the number of injuries for all participants.

The analysis of correlations between the number of injuries and 12 tests was performed. The analysis was performed using Spearman's rank correlation for the whole group $(n=102)$ without the division. The number of injuries was statistically significantly correlated only for the Shoulder Mobility test for the right side. The value of the correlation coefficient was $r=0.20$ and statistically significantly $p=0.0451$. The positive value of the correlation coefficient indicates a relation between the increase in the value of one variable and the increase in the other variable. In the analysis of the strength of this relation a weak, but statistically significant relation was noted. For other tests no statistically significant variation with the number of injuries was noted. 
Table $\mathbf{6}$. Spearman's rank correlation between individual tests and the number of injuries for all participants $(n=102)$

\begin{tabular}{lccc}
\hline \multicolumn{1}{c}{ Variable } & Spearman's R correlation coefficient & t test & Value of $p$ \\
\hline 1. Deep Squad \& the number of injuries & 0.120 & 1.20 & 0.2331 \\
2. Hurdle Step L \& the number of injuries & -0.040 & -0.40 & 0.6896 \\
3. Hurdle Step R \& the number of injuries & -0.050 & -0.54 & 0.5919 \\
4. In-line Lunge L \& the number of injuries & -0.150 & -1.47 & 0.1453 \\
5. In-line Lunge R \& the number of injuries & -0.060 & -0.59 & 0.5555 \\
6. Shoulder Mobility L \& the number of injuries & 0.060 & 0.61 & 0.5417 \\
7. Shoulder Mobility R \& the number of injuries & 0.200 & 2.03 & $0.0451^{*}$ \\
8. ASLR L \& the number of injuries & 0.030 & 0.31 & 0.7580 \\
9. ASLR R \& the number of injuries & 0.120 & 1.24 & 0.2189 \\
10. Trunk Stability Push-up \& the number of injuries & -0.010 & -0.09 & 0.9264 \\
11. Rotational Stability L \& the number of injuries & -0.004 & -0.04 & 0.9666 \\
12. Rotational Stability R \& the number of injuries & 0.040 & 0.38 & 0.7024 \\
\hline
\end{tabular}

"Statistically significant $p<0.05$.

Table 7 presents the results of Spearman's rank correlation test taking into account the number of points scored in individual tests and the number of injuries of the lower range players (14-17 points).

Table 7. Spearman's rank correlation between individual tests and the number of injuries of players in the lower range (1417 points, $n=45$ )

\begin{tabular}{lccc}
\hline \multicolumn{1}{c}{ Variable } & Spearman's R correlation coefficient & t test & Value of $p$ \\
\hline 1. Deep Squad \& the number of injuries & -0.0008 & -0.006 & 0.9957 \\
2. Hurdle Step L \& the number of injuries & -0.3900 & -2.800 & $0.0077^{*}$ \\
3. Hurdle Step R \& the number of injuries & -0.2400 & -1.620 & 0.1126 \\
4. In-line Lunge L \& the number of injuries & -0.0800 & -0.500 & 0.6186 \\
5. In-line Lunge R \& the number of injuries & -0.1200 & -0.810 & 0.4246 \\
6. Shoulder Mobility L \& the number of injuries & 0.1000 & 0.670 & 0.5056 \\
7. Shoulder Mobility R \& the number of injuries & 0.3200 & 2.190 & $0.0342^{*}$ \\
8. ASLR L \& the number of injuries & -0.1100 & -0.710 & 0.4842 \\
9. ASLR R \& the number of injuries & 0.0200 & 0.140 & 0.8896 \\
10. Trunk Stability Push-up \& the number of injuries & -0.0700 & -0.440 & 0.6601 \\
11. Rotational Stability L \& the number of injuries & 0.0400 & 0.280 & 0.7791 \\
12. Rotational Stability R \& the number of injuries & 0.0500 & 0.360 & 0.7241 \\
\hline
\end{tabular}

" $p<0.05$ statistically significant.

The analysis of relationship between the number of injuries and the 12 analyzed tests was performed using Spearman's rank correlation for the players of the lower range (with the score of 14-17 points). The number of injuries correlated significantly statistically within pairs of variables of the Hurdle Step of the left side and the Shoulder Mobility test of the right side. The analysis of the Hurdle Step of the left side indicated that the value of correlation 
was $r=-0.39$ and statistically significant $p=0.0077$. The negative value of the correlation coefficient indicates the relation between the decrease in the value of one variable and the increase in the other variable. The analysis of the strength of the above relation moderate relation was noted. In Shoulder Mobility test of the right side it was noted that the value of correlation was $r=0.32$ and statistically significant $p=0.0342$. The positive value of the correlations coefficient indicates the relation between the increase in one variable and the increase in the other variable. In the analysis of the strength of the above relation moderate dependence was noted. No statistically significant variation with the number of injuries was noted for other tests. In spite of the lack of statistical significance in the correlation between the number of injuries and the Hurdle Step test of the left side, a trend towards significance was noted. The negative value of the correlation coefficient $(r=-0.24)$ informs about the decrease in the value of one variable with the increase in value of the other variable.

Table 8 presents the results of Spearman's rank correlation test taking into account the number of points scored in individual tests and the number of injuries of players in the upper range (18-21 points).

Table 8. Spearman's rank correlation between individual tests and the number of injuries for players in the upper range (1821 points, $n=57$ )

\begin{tabular}{lccc}
\multicolumn{1}{c}{ Variable } & Spearman's R correlation coefficient & t test & Value of $p$ \\
\hline 1. Deep Squad \& the number of injuries & 0.18 & 1.33 & 0.1881 \\
2. Hurdle Step L \& the number of injuries & 0.07 & 0.51 & 0.6117 \\
3. Hurdle Step R \& the number of injuries & 0.07 & 0.52 & 0.6029 \\
4. In-line Lunge L \& the number of injuries & -0.33 & -2.56 & $0.0133^{*}$ \\
5. In-line Lunge R \& the number of injuries & & & \\
6. Shoulder Mobility L \& the number of injuries & & & 0.72 \\
7. Shoulder Mobility R \& the number of injuries & & 1.53 & 0.1307 \\
8. ASLR L \& the number of injuries & 0.10 & 0.57 & 0.5736 \\
9. ASLR R \& the number of injuries & 0.20 & -0.31 & 0.7595 \\
10. Trunk Stability Push-up \& the number of injuries & 0.08 & -0.04 & 0.21 \\
11. Rotational Stability L \& the number of injuries & 0.03 & & 0.8363 \\
12. Rotational Stability R \& the number of injuries & & \\
\hline
\end{tabular}

* Statistically significant $p<0.05$.

The analysis of relations between the number of injuries and 12 tests was performed using Spearman's rank correlation for the players of the upper range (with scores of 18-21 points). The number of injuries correlated statistically significantly only for the In-line Lunge test of the left side. The correlation coefficient was $r=-0.33$ and statistically significant $p=0.0133$. The negative value of the correlation coefficient indicates the relation between the increase in one variable and the decrease in the other variable. The analysis of the strength of the above relations moderate dependence was noted. For other tests no statistically significant variation was noted. 


\section{Logistic regpession drawings}

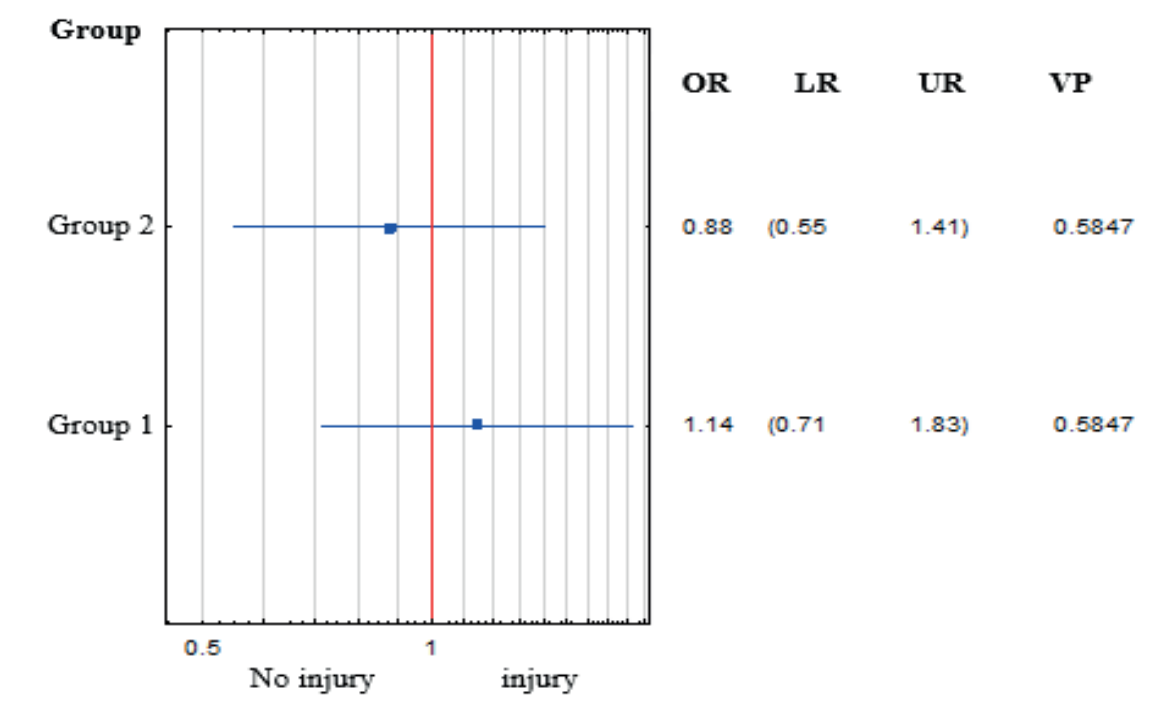

OR - odds ratio; LR - lower range; UP - upper range; VP - value of $p$

Figure 1. Forest diagram for injuries and groups

The results of univariate logistic regression showed than injuries more often occurred in group 1. Forest diagram indicates the direction of increased chance of injury in players in the lower range of scores: $O R=1.14$ (95\% CL; $0.71: 1.83)$.

\section{Discussion}

It is undisputable that physical activity creates a number of health benefits, however it also carries some risks. An increased risk to health and life usually takes place in competitive sport where trauma and body injury are nothing unusual. A constantly growing number of scientific studies analyzing the risk of sports injuries in soccer players shows the essence of the problem. A continuous progress in motor and technical preparation of players is a result of adaptation to the growing dynamics of the game. As a consequence systematic the need to shorten the reaction time of a player with the ball can be observed which is conducive to a further increase in the number of injuries reported by the players in soccer clubs. With the awareness that the analysis of motor abilities as an isolated approach provides insufficient feedback on the condition of players, the search began for other methods assessing the fitness of the motor system as a cohesive whole. FMS is a screen test which analyses the quality of basic movement patterns which are the necessary foundations for normal movement of body in space. The FMS test battery consists of seven movement screens and three additional clearing tests which are assessed in the four-degree scale from 0 to 3 points. An additional advantage of the tests is the possibility of observing deficiencies and asymmetries within the whole biokinematic chain of a studied person, as well as the ability to estimate the risk 
of injury. During movement activities analyzed body parts co-operate together, creating favorable conditions for observation of the musculoskeletal system as a cohesive whole (Bangsbo et al., 2006; Hadała et al., 2006; Kiesel et al., 2011).

A review of the currently available literature brings out a large number of studies focusing on the Functional Movement Screen. However, the vast majority of the publications analyze the effect of the FMS test results on the progress of mobility, stability, quality of movement patterns, and modification of training units. There are still relatively few studies confirming the ability of the FMS test to identify individuals with a potentially higher risk of injury in soccer. J.C. Tee et al. (2016) in their study noted significantly lower results of the test in players who sustained a serious injury compared to the healthy group. It was noted that the above phenomenon occurred as a result of significant differences in assessment within the In-line Lunge (ILL) and Active Straight Leg Raise (ASLR) tests. According to the authors, the ASLR test is characterized by the highest sensitivity as an injury risk indicator (Tee, Klingbiel, Collins, Lambert, Coopoo, 2016). In the study of D. Zalai et al. (2015) carried out on a group of 20 professional soccer players it was noted that the mean number of injuries per one player was 1.5 . In the analysis of the Hurdle Step and Deep Squat tests the authors noted a statistically significant correlation with injury proneness. In the analysis of the Hurdle Step test statistical significance was noted between the results of the movement pattern and injuries within the ankle joint. Similarly, statistically significant correlation was noted between the results of the Deep Squat test and injuries of the knee and hip joints (Zalai et al., 2015).

Another study was performed on a group of 100 physically active students in order to identify relations between the FMS test results and the injury history. In the analysis of the results reported by the authors it can be noted that for persons in the lower range (range of points $\leq 17, n=46$ ) the risk of a light injury is 4.7 times higher than persons in the upper range (range of points $>17, n=54$ ). In the analysis of the group of players in the lower range it can be noted that 22 persons were injured and for the other 24 participants no injuries within the motor system were noted. In the group of players in the upper range it can be noted that a definitely greater number of people $(n=34)$ did not sustain injuries (Shojaedin et al., 2014).

Our study included 102 players regularly training in a sport soccer club KKS Lech Poznan. In the analysis of the results of test of all players it was noted that the mean score in FMS test was 17.7 points and the mean number of injuries per one player was 1.28. The lowest scores were noted in the Deep Squat test where the mean was 2.19 points. After dividing the participants into two groups where the criterion was sustaining injury or not, it was noted that the vast majority, i.e. $77.45 \%$ of participants sustained an injury in the six months of the study. In the analysis of the results of the group of players in the lower range (with FMS scores of 14-17, $n=45$ ) it was noted that the lowest values were noted in the Deep Squat test where the mean was 1.93 points. The mean score for the whole test for persons in the lower range was 16.07 points and the mean number of injuries per one player in this group was 1.27. In the group of upper range players (with the FMS score of 18-21 points, $n=57$ ) it was also noted that the lowest scores were in the Deep Squat test. The mean score in the Deep Squat test of the analyzed group was 2.39 points. The analyzed group of players had a mean total score of 18.98 points and the mean number of injuries per one player was 1.3.

The adopted research hypothesis was not confirmed within the analyzed group of players. In the analysis of Spearman's rank correlation between the total FMS score and the number of injuries, statistical significance was not noted in the analyzed groups. In the next stage, the analysis of Spearman's rank correlation between the scores in individual tests and the number of injuries was performed. Within the whole study group $(n=102)$ it was noted that 
the number of injuries correlated statistically significantly only in case of the Shoulder Mobility test of the right side. The value of the correlation coefficient was $r=0.20$ and statistically significant $p=0.0451$. For players in the lower range (with the score of $14-17$ points, $n=45$ ) the number of injuries correlated statistically significantly within pairs of variables of the Hurdle Step test of the left side and Shoulder Mobility test of the right side. In the analysis of the Hurdle Step test of the left side it was noted that the value of correlation was $r=-0.39$ and statistically significant $p=0.0077$. For the Shoulder Mobility test of the right side the value of correlation was $r=0.32$ and statistically significant $p=0.0342$. For players in the upper range (with the score of $18-21$ points, $n=57$ ) it was noted that the number of injuries was statistically significantly correlated only for the In-line Lunge test of the left side. The value of the correlation coefficient was $r=-0.33$ and statistically significant $p=0.0133$. For other tests no statistically significant variation was noted. The analysis of the results of univariate logistic regression showed that injuries occurred more often in the group of lower range players. The forest diagram shows the direction of an increased risk of injury in players of the lower range of score: $\mathrm{OR}=1.14(95 \% \mathrm{CL} ; 0.71: 1.83)$.

\section{Conclusions}

1. On the basis of the performed tests it was noted that $77.45 \%$ of the studied players sustained a sports injury in a six month period. The mean number of injuries per one player within the whole study group was 1.28 injuries/ person. It was noted that the mean number of injures, taking into account the division of players into the upper and lower ranges, was 1.3 and 1.27 injuries/person, respectively. The situation could have been caused by the fact that the players of upper range representing the higher sport level took a larger share in the match units.

2. No statistical significance was noted between the total FMS score and the number of injuries.

3. Statistically significant correlation was found between the number of injuries and the scores in the Hurdle Step test of the left side for the group of lower range players and the In-line Lunge test of the left side for the group of upper range players. The negative value of correlation coefficients suggests that with the increase in the score in the Hurdle Step test of the left side for the lower range players and the In-Lunge test of the left side for the upper range players the number of injuries decreased.

4. The forest diagram indicates the direction of increased risk of injury in the players of the lower score range.

\section{Referencees}

Adamczyk, G. (2005). Injuries in football. Forum Trenera, 1, 36-39.

Adamczyk, J.G., Pepłowski, M., Boguszewski, D., Białoszewski, D. (2012). Functional evaluation of athletes practicing weightlifting using the functional movement screen test. Medycyna sportowa, 28 (4), 267-276.

Bangsbo, J., Mohr, M., Krustru, P. (2006). Physical and metabolic demands of training and match-play in the elite football player. Journal of Sports Sciences, 24 (7), 665-674.

Główny Urząd Statystyczny (GUS) (2017). Physical Culture in Poland in 2016. Retrieved from: https://stat.gov.pl/obszary-tematyczne/ kultura-turystyka-sport/sport/kultura-fizyczna-w-polsce-w-2016-r-,12,1.html.

Grygorowicz, M., Głowacka, A., Wiernicka, M. (2010). Comprehensive physiotherapeutic assessment as the basis for the primary prevention of sports injuries. Nowiny lekarskie, 79 (3), 240-244.

Hadała, M., Bieganowski, K., Wierzbowska, C., de Bernardo Tajedor, N., Snela, S. (2006). Traumatism among football players and methods of work of the medical team in selected Polish and Spanish football clubs. Medycyna sportowa, 22 (5), 272-276.

Kiesel, K., Plisky, P., Butler, R. (2011). Functional movement test scores improve following a standardized off-season intervention program in professional football players. Scandinavian Journal of Medicine \& Science in Sports, 21 (2). 
Kiesel, K., Plisky, P.J., Voight, M.L. (2007). Can serious Injury in Professional Football be Predicted by a Preseason Functional Movement Screen? North American Journal of Sports Physical Therapy, 2 (3).

Lemiesz, G., Iwańczyk, K., Biernat, R., Godlewski, J., Szymański, M., Biernat, U., Tajchman, L., Sieklucka, E. (2013). Application of the Functional Assessment test in practice. Praktyczna fizjoterapia i rehabilitacja, 39, 4-11.

Minick, K., Kiesel, K.B., Burton, L., Taylor, A., Plisky, P., Butler, R.J. (2010). Interrater Reliability of the Functional Movement Screen. Journal of Strength Conditioning Research, 24 (2).

Rzepka, R. (2009). Functional training and the possibilities of its use in training footballers. In: T. Grzybczak, R. Więcek, A. Stuła (eds), Theoretical and practical aspects of modern football (209-244). Opole: Politechnika Opolska.

Shojaedin, S.S., Letafatkar, A., Hadadnezhad, M., Dehkhoda, M.R. (2014). Relationship between functional movement screening score and history of injury and identifying the predictive value of the FMS for injury. International Journal of Injury Control and Safety Promotion, 21 (4), 355-360.

Tee, J.C., Klingbiel, J.F., Collins, R., Lambert, M.I., Coopoo, Y. (2016). Preseason Functional Movement Screen Component Tests Predict Severe Contact Injuries in Professional Rugby Union Players. J Strength Conditioning Research, 30 (11), 3194-3203.

Zalai, D., Panics, G., Bobak, P., Csáki, I., Hamar. P. (2015). Quality of functional movement patterns and injury examination in elite-level male professional football players. Acta Physiologica Hungarica, 102 (1), 34-42

Żołnowski, B., Wrona-Żołnowska, L., Gębska, M., Wojciechowska, A., Żyżniewska-Banaszak, E. (2013). Traumatism of youth practicing football at the age of 15-19. Rocznik Pomorskiej Akademii Medycznej w Szczecinie, 59 (1), 120-123.

Cite this anticle aS: Kryger, K., Wieczorek, A., Wieczorek, J., Śliwowski, R. (2019). The influence of functional movement screen results on the frequency of sports injuries in soccer players. Central European Journal of Sport Sciences and Medicine, 3 (27), 41-53. DOI: 10.18276/cej.2019.3-04. 